\title{
Strategies and developments of immunotherapies in osteosarcoma (Review)
}

\author{
JIA WAN, XIANGHONG ZHANG, TANG LIU and XIANGSHENG ZHANG
}

Department of Orthopedics, The Second Xiangya Hospital, Central South University, Changsha, Hunan 410011, P.R. China

Received November 13, 2014; Accepted October 27, 2015

DOI: $10.3892 / 01.2015 .3962$

\begin{abstract}
Osteosarcoma (OS) is a frequently observed primary malignant tumor. Current therapy for osteosarcoma consists of comprehensive treatment. The long-term survival rate of patients exhibiting nonmetastatic OS varies between $65-70 \%$. However, a number of OS cases have been observed to be resistant to currently used therapies, leading to disease recurrence and lung metastases, which are the primary reasons leading to patient mortality. In the present review, a number of pieces of evidence provide support for the potential uses of immunotherapy, including immunomodulation and vaccine therapy, for the eradication of tumors via upregulation of the immune response. Adoptive T-cell therapy and oncolytic virotherapy have been used to treat OS and resulted in objective responses. Immunologic checkpoint blockade and targeted therapy are also potentially promising therapeutic tools. Immunotherapy demonstrates significant promise with regard to improving the outcomes for patients exhibiting OS.
\end{abstract}

\section{Contents}

1. Introduction

2. Immunomodulation

3. Adoptive T-cell immunotherapy

4. Vaccines

5. Immunologic checkpoint blockade

6. Oncolytic virotherapy

7. Conclusion

Correspondence to: Dr Tang Liu, Department of Orthopedics, The Second Xiangya Hospital, Central South University, 139 Renmin Road, Changsha, Hunan 410011, P.R. China E-mail: liutang1981@126.com

Key words: osteosarcoma, immunotherapy, immunomodulation, adoptive T-cell immunotherapy, vaccines, immunologic checkpoint blockade, oncolytic virotherapy, targeted therapy

\section{Introduction}

Osteosarcoma (OS) is the most frequently observed primary bone tumor, typically affecting children and adolescents (1). The long-term survival rate of patients exhibiting nonmetastatic OS varies between $65-70 \%$, due to the introduction of multiagent chemotherapy, as well as the improvement of surgical techniques (2). However, the survival rate of patients exhibiting detectable metastases remains unchanged (3). The rapid development of metastatic lesions, and resistance to chemotherapy, are the primary factors that mean that patients eventually develop pulmonary metastases and succumb to disease (4). The poor survival rates of patients exhibiting OS with metastases suggest that the development of novel therapies, including immunotherapies based on upregulation of the immune response in patients exhibiting tumors, is essential (2). The immune system is significant for tumor control, and appropriate command of the immune system may provide an effective therapeutic approach for the treatment of OS.

The present review focuses on the current strategies and developments in immunotherapies for the treatment of OS, including immunomodulation, adoptive T-cell immunotherapy, vaccines, immunologic checkpoint blockade, oncolytic virotherapy and targeted therapy. As a nonspecific immunotherapy, immunomodulation involves activation of the innate immune system, leading to upregulation of the action of monocytes, macrophages and natural killer (NK) cells, in the hope that these will spontaneously attack tumors (3). Adoptive T-cell immunotherapy and vaccines seek to transfer T-cells or tumor-associated factors into patients, therefore enhancing or inducing an antitumor immune response via manipulation of the adaptive immune system (5). Immunological checkpoint blockage and targeted therapy refer to the identification of specific targets in tumors, leading to inhibition of the signaling pathways involved in cancer onset and progression (6). Oncolytic virotherapy uses replication competent viruses to selectively infect and damage tumor cells, and avoids causing harm to normal tissues (7). The present review will provide an overview of the above-mentioned therapies.

\section{Immunomodulation}

Muramyl tripeptide phosphatidylethanolamine (MTP-PE) is a synthetic lipophilic analogue of muramyl dipeptide (8). Encapsulation of MTP-PE into multilamellar liposomes 
(L-MTP-PE) has allowed targeted delivery of MTP-PE to monocytes and macrophages, which induces them to become activated and tumoricidal (8). This tumoricidal activity is associated with increased secretion of cytokines, including tumor necrosis factor- $\alpha$, interleukin (IL)-6, and IL-1 $\beta$, which are proinflammatory molecules (9). The rationale underlying the use of L-MTP-PE in the treatment of OS is to stimulate an inflammatory response that is able to eradicate any residual micrometastases that were not eliminated by previous adjuvant chemotherapy (9). In a preclinical trial in dogs exhibiting spontaneous OS, administration of L-MTP-PE following tumor excision improved disease-free survival to 222 days, compared with a disease-free survival period of 77 days in dogs that received placebo (10). Based on preclinical findings, a phase II study using L-MTP-PE was undertaken in patients exhibiting OS recurrence, following total surgical resection of all detectable disease. Patients that received 24 weeks of L-MTP-PE therapy demonstrated a significantly increased time to recurrence of 9 months, compared with 4.5 months for the control group. However, patients that received 12 weeks of L-MTP-PE therapy demonstrated no significant difference in time to recurrence compared with controls (11). In a subsequent phase IIb trial, the tolerability of L-MTP-PE, administered in combination with ifosfamide, was investigated in 9 patients exhibiting OS and lung metastases. There was no increase in the anticipated toxicity of ifosfamide and no delay in administration of ifosfamide (12). The Children's Oncology Group Intergroup-0133 was a randomized prospective trial, in which patients exhibiting newly diagnosed OS, without clinically detectable metastatic disease, were recruited in order to investigate the addition of L-MTP-PE and/or ifosfamide to standard high-dose methotrexate with leucovorin rescue+doxorubicin/Adriamycin+cisplatin (MAP) therapy. The first analysis of Children's Oncology Group Intergroup-0133, published in 2005, reported a significant interaction between L-MTP-PE and ifosfamide, and no significant impact of L-MTP-PE on event-free survival (EFS) (13). In the subsequent analysis with increased follow-up times, this interaction was no longer statistically significant. A 2008 report demonstrated that the addition of MTP-PE in concurrent therapy was able to improve overall survival from 70 to $78 \%$ (14). Additionally, in patients exhibiting primary metastatic OS, improvements in event-free and overall survival were observed, however, statistical analysis was not able to achieve a conventional level of statistical significance (15). A compassionate study of L-MTP-PE treatment for patients with metastatic and recurrent OS was completed in December 2012, and additionally demonstrated a survival advantage for the patients who were administered L-MTP-PE (16). More recently, it has been suggested that the induction of macrophage antitumor activity by L-MTP-PE is dependent on interferon (IFN)- $\gamma$, which may be capable of enhancing liposome uptake and improving the response to bacterial components. This is relevant for the optimization of L-MTP-PE therapy in OS patients (17). Based on a Markov model analysis, it has been identified that the addition of mifamurtide to chemotherapeutic regimens increased survival time in children exhibiting OS (18). The relative quality-adjusted life years and life years gained from treatment with L-MTP-PE plus chemotherapy, increased by $16.3 \%$ and $15.7 \%$, respectively, compared with chemotherapy treatment alone (18). However, the benefit of addition of L-MTP-PE to standard chemotherapy regimens, as an adjuvant in the treatment of patients exhibiting high-grade OS, remains to be fully elucidated. Further investigation is necessary in order to define the role of L-MTP-PE in the treatment of OS. L-MTP-PE was approved by the European Medicines Agency in 2008 for the treatment of newly diagnosed, nonmetastatic OS, in combination with chemotherapy, however, the Food and Drug Administration has not approved L-MTP-PE in the USA.

IFNs are a group of pleiotropic cytokines that may cause antiviral, antitumor, apoptotic, antiangiogenic and cellular immune responses (19). The mechanisms of antitumor action of IFNs may be divided into direct cytostatic effects and indirect effects of cytotoxic T-cell and B-cell activation, leading to the secretion of antibodies (20). There are three subtypes of IFN: IFN- $\alpha$, IFN- $\beta$ and IFN- $\gamma$; IFN- $\alpha$ and IFN- $\beta$ activate the type I IFN receptors, while IFN- $\gamma$ binds distinctly to the type II IFN receptors (20). IFN- $\alpha$ has been the most commonly used IFN in OS immunotherapy (21). In 1977, Strander et al (22) demonstrated that IFN- $\alpha$ was capable of inhibiting the growth of human OS cells in vitro. An additional study demonstrated that IFN- $\alpha$ is able to arrest the growth of tumors in nude mice transplanted with human OS cells (23). Manara et al (24) revealed that type I IFNs demonstrated a significant inhibitory effect on multidrug-resistant P-glycoprotein overexpressing OS cells in vitro. However, to the best of our knowledge, little published data exists on the clinical efficacy of type I IFNs. In a pilot study of patients demonstrating nonmetastatic OS, the 5-year disease-free survival rate was $63 \%$ in patients that had been treated with single-agent adjuvant IFN- $\alpha$ over a period of 3-5 years (25). A Scandinavian study demonstrated an apparent increase in relapse-free survival rates in patients exhibiting primary high-grade localized OS, who received IFN- $\alpha$ as a single adjuvant to surgery (21). In addition, pegylation of IFN- $\alpha-2 b$ may decrease clearance, thereby increasing its plasma half-life. This may improve efficacy and offers the major advantage of an increased maximum-tolerated dose without unacceptable toxicity, compared with non-pegylated IFN- $\alpha(26,27)$. Currently, there is an ongoing randomized trial of the European and American Osteosarcoma Study group (EURAMOS 1) in patients exhibiting localized OS with positive histological responses to neoadjuvant chemotherapy. The patients were administered chemotherapy with or without pegylated IFN- $\alpha-2 b$; however, the results remain to be published.

Another immunomodulatory approach that is currently being investigated for the treatment of OS is utilization of granulocyte macrophage-colony-stimulating factor (GM-CSF). An in vitro trial performed by Postiglione et al (28) demonstrated that GM-CSF was capable of inducing differentiation and apoptosis in the SaOS-2 human OS cell line. In a phase I study, aerosol delivery of GM-CSF was demonstrated to be feasible, safe and effective in a number of patients (29). A total of 7 patients were enrolled; 1 patient exhibiting Ewing's sarcoma demonstrated a complete response, 1 patient exhibiting melanoma demonstrated a partial response and 3 patients demonstrated stabilization of pulmonary metastases for 2-6 months (29). Furthermore, GM-CSF treatment 
was demonstrated to be feasible and possess low toxicity in a phase II trial of patients exhibiting first isolated pulmonary recurrence of OS (30). A total of 37 patients demonstrated a second recurrence of OS, with a median event-free survival time of 4.3 months. The majority of recurrences occurred within 1 year of study enrollment, and 2- and 3-year EFS from the time of enrollment was 12.9 and $7.8 \%$, respectively. However, no detectable immunostimulatory effect was observed for tumor relapse and lung metastases (30). Additionally, another immunomodulatory approach that is currently being investigated is tumor-specific oncolytic adenovirus delivery of GM-CSF, which demonstrated increased antitumor activity in human lung and mouse melanoma models, when compared with phosphate-buffered saline treatment (31). These results suggest that this oncolytic agent may be an appealing approach for the treatment of OS.

IL-2 possesses the ability to stimulate and upregulate Tand NK cells, and is able to activate lymphocytes so that they become lymphocyte-activated killer cells (6). A study was performed in which high doses of IL-2 were administered to 10 children exhibiting progressive or metastatic solid tumors, including 4 patients with OS and 2 with Ewing's sarcoma. Of the 4 OS patients, 2 achieved complete responses with a median follow-up time of 28 months; the remaining OS and Ewing's sarcoma patients demonstrated progression of disease (32). In a clinical trial, 18 children exhibiting localized OS received IL-2, alternated with pre- and post-operative multiple chemotherapy. The results demonstrated that IL-2 was able to induce immune activation despite the intensive chemotherapy, and suggested that NK cells may possess a role in the control of OS (33). Toxicity during IL-2 therapy may induce a number of symptoms, including gastrointestinal (nausea, vomiting and diarrhea), constitutional (fatigue and anorexia) and cardiac (tachycardia and hypotension) (32). Guma et al (34) demonstrated that aerosol IL-2 treatment may increase lung NK cell numbers via stimulation of local NK cell proliferation, and this proliferation was observed to be organ specific, without IL-2-associated systemic toxicities. In addition, the therapeutic efficacy of aerosol treatment with IL-2+NK cells in inducing metastatic regression and increasing overall survival was observed to be higher, compared with aerosol IL-2 treatment alone or treatment with NK cells without aerosol IL-2 $(34,35)$. In a murine OS transplantation model, an intraperitoneal injection of IL-2 monoclonal antibody was administered (S4B6) into mice that had received transplanted LM8 osteosarcoma cells, and it was identified that the number of pulmonary metastatic colonies and tumor size were significantly reduced (36). Additionally, in a phase I study, intravenous IL-2 gene delivery utilizing cationic liposome-DNA complexes has been revealed to elicit antitumor activity in mouse and dog models exhibiting advanced tumor metastases, and it has been identified to be safe and well-tolerated at low doses (37). This represents an encouraging result that requires additional investigation.

\section{Adoptive T-cell immunotherapy}

Adoptive T-cell therapy is based on the use of allogeneic or autologous T-lymphocytes, which exhibit antitumor activity and mediate objective clinical responses (38). Adoptive T-cell therapy involves the ex vivo isolation of T-cells, manipulation and subsequent infusion into patients (38). Recent advances include the successful use of genetic engineering to retarget T-cells prior to their transfer into patients, which resulted in increased accuracy of targeting of the antigens expressed by tumors (39). These include T-cell receptor (TCR)-modified T-cells, chimeric antigen receptor (CAR)-modified T-cells and NK cells (39).

TCRs are composed of $\alpha$ and $\beta$ chains, which form heterodimers (40). TCRs recognize intracellularly processed peptides, which are presented on major histocompatibility complex (MHC) molecules on the cell surface (41). T-cells with particularly positive antitumor responses may be isolated from patients. Following isolation, genes encoding TCRs are cloned and inserted into retrovirus or lentivirus vectors, and subsequently utilized for infection of autologous T-cells from the patient to be treated (41). One of the initial studies in humans with TCR-redirected T-cells focused on the treatment of melanoma using autologous polyclonal T-cells that expressed melan-A (MART-1) specific $\alpha / \beta$ TCRs. A total of $2 / 15$ lymphodepleted melanoma patients demonstrated an objective regression of metastatic lesions without significant toxicity (42). A subsequent trial that utilized T-cells expressing high affinity MART-1 and gp100-specific $\alpha / \beta$ TCRs, resulted in an increased objective response, while a number of patients demonstrated toxicities, including erythematous skin rash, hearing loss, anterior uveitis and vitiligo, due to the destruction of normal tissues that were expressing target antigens (43). New York-esophageal squamous cell carcinoma-1 (NY-ESO-1) is a member of the cancer-testis antigen family, which is expressed in $\sim 80 \%$ of synovial carcinoma cases, and $30-40 \%$ of breast, thyroid, urothelial, prostate, hepatic, esophageal and gastric cancer cases, as well as in melanoma and neuroblastoma (44). In a clinical trial, objective clinical responses were observed in 4/6 patients exhibiting synovial cell sarcoma and 5/11 patients with melanoma, following treatment with NY-ESO-1-specific TCR T-cells subsequent to preparative chemotherapy, and no significant toxicities were observed (45). Additionally, a study (NCT01967823) is currently ongoing for patients with metastatisis, combining a conditioning regimen of cyclophosphamide and fludarabine with NY-ESO-1-specific TCR T-cells (5). TCRs that target melanoma-associated antigen (MAGE) have additionally been evaluated. In a trial performed by Morgan et al (46), 9 cancer patients were treated with adoptive cell therapy utilizing autologous anti-MAGE-antigen (A)3 TCR engineered T-cells. The TCR was derived from the immunization of human leukocyte antigen (HLA)-A*0201 transgenic mice, which recognized epitopes in MAGE-A3/A9/A12. In these 9 patients, 5 experienced clinical regression of their cancer, however, 3 patients exhibited mental status changes, and 2 patients lapsed into comas and subsequently died. Postmortem analysis indicated that MAGE-A12 was expressed in the human brain. Linette et al (47) initiated clinical testing of engineered T-cells that expressed an affinity-enhanced TCR against HLA-A*01-restricted MAGE-A3, for patients exhibiting myeloma and melanoma. The initially treated patients developed cardiogenic shock and died, due to recognition of an unrelated peptide that was derived from the striated muscle-specific protein titin. The carcinoembryonic antigen (CEA) has additionally been targeted in adoptive immunotherapy; however, recognition of normal tissue that expressed 
low levels of CEA leading to induction of severe transient colitis has additionally been reported (48). Although there are clinical limitations in adoptively transferred TCR-modified T-cells, the above-mentioned clinical studies have additionally demonstrated the potential applications in the treatment of OS.

CARs are synthetic receptors that consist of an extracellular single-chain variable fragment $(\mathrm{scFv})$ derived from monoclonal antibodies, a transmembrane domain and an endodomain, which contains a cluster of differentiation (CD) $3 \zeta$ chain signaling domain and costimulatory molecules, including CD27 (49), CD28 (50), CD244 (51), 4-1BB (52) and OX40 (53). First generation CARs contain only the $\mathrm{CD} 3\}$ chain signaling domain, second generation CARs incorporate one costimulatory molecule and third generation CARs combine two costimulatory molecules (39). The scFv domain binds directly to target cell surface epitopes and does not require antigen presentation on MHC molecules, thus rendering CAR T-cells resistant to tumor escape mechanisms associated with HLA downmodulation and altered processing escape mechanisms (54). CAR-engineered T-cells have been generated against a number of tumor-associated antigens for OS, including human epidermal growth factor receptor 2 (HER-2) and IL-11 receptor alpha (R $\alpha$ ). HER-2 has been observed to be expressed in a proportion of OS cases and is known to be a risk factor for poor patient outcomes (55). Ahmed et al (56) generated a second generation HER-2-specific CAR, containing a $\mathrm{CD} 28 \zeta$ signaling domain, via retroviral transduction, and induced regression of established OS xenografts in locoregional and metastatic mouse models. In a follow-up study, administration of HER-2-specific CAR T-cells was observed to significantly reduce the number of tumor-initiating cells in bulk tumors, as judged by decreased sarcosphere-forming efficiency in OS cells (57). However, a clinical trial has served to highlight the safety considerations of HER-2-CAR T-cell therapy. A patient exhibiting colon cancer that had metastasized to the lungs and liver was treated with third generation HER-2-specific CAR T-cells, containing CD28, 4-1BB and a CD3ל signaling domain (58). The patient experienced respiratory distress and pulmonary infiltration $<15$ min following cell infusion and died 5 days subsequent to treatment (58). CARs for the targeting of IL-11R $\alpha$ have additionally been evaluated in adoptive immunotherapy. IL-11 is a member of a family of pleiotropic cytokines and is observed to be overexpressed on OS lung metastases (59). IL-11 is involved in adipogenesis, osteoclastogenesis, neurogenesis, megakaryocyte maturation, platelet production and the activation of the Janus kinase-signal transducer and activator of transcription pathway (60). An IL-11R $\alpha$-CAR-specific T-cell strategy was employed in a trial for the treatment of OS. The metastatic OS model developed regression of pulmonary metastases with no organ toxicity (59). The above-mentioned preclinical studies have demonstrated the encouraging antitumor activity of CAR T-cells, and these results justify the active investigation of the suitability of CAR T-cell therapy for the treatment of OS.

For TCR- and CAR-modified T-cell strategies, numerous preclinical and clinical studies have documented the benefits of adoptive immunotherapy (39). However, several challenges remain in the development of safe and effective T-cell therapies, including target antigen selection, in vivo $\mathrm{T}$-cell expansion and persistence, the inhibitory tumor microenvironment and T-cell trafficking to tumor sites (39). In order to overcome these limitations, T-cell therapy combined with blocking antibodies has been developed and evaluated. For example, blocking of programmed death receptor 1 (PD-1), in combination with the adoptive transfer of HER-2-CAR T-cells, resulted in enhanced antitumor effects in a clinical melanoma model (61).

In addition, $\mathrm{NK}$ cells are being tested in adoptive transfer strategies. As a part of the innate immune system, NK cells are characterized by their cytotoxic and regulatory functions against infections and malignancies (62). NK cells have the ability to lyse malignant and infected cells, with no need for prior immunization or MHC restriction, and their activation is dependent on the balance between inhibitory and activating signals from invariant receptors (63). Clinical data has demonstrated that NK cells may possess a significant role in OS tumor development and treatment responses $(64,65)$. The susceptibility of tumor cells to NK cell killing correlates negatively with the expression of HLA class I antigens (66). With respect to OS, loss or downregulation of HLA class I expression has been observed in primary and metastatic tumors (67), thus indicating increased susceptibility to NK cell killing. In a preclinical trial, Cho et al (68) tested the cytotoxicity of expanded NK cells against various cell lines (Ewing's sarcoma, rhabdomyosarcoma, neuroblastoma and osteosarcoma) and assessed the therapeutic effects of NK cell infusions in immunodeficient (non-obese diabetic/severe combined immunodeficient IL-2RG null) mice. The results of this study revealed that solid tumors were potentially susceptible to NK cell cytotoxicity. In addition, another study has revealed that the cytolytic potential of patient-derived NK cells may be potentiated and directed toward OS cells via cetuximab-mediated antibody-dependent cell-mediated cytotoxicity (69). NK-92 is a cell line isolated from a patient with lymphoma, which demonstrates high cytotoxic activity and may be expanded (70). Patients exhibiting advanced, treatment-resistant malignancies received an infusion of NK-92 cells, and a number of encouraging responses were observed in patients with advanced lung cancer, however, no significant response in OS was observed (71). To enhance NK cell functioning and OS sensitivity, Chang et al (72) developed a genetically modified NK cell that was composed of the NK cell activating molecule NKG2D, plus two key signaling molecules, DAP10 and CD3 $\zeta$. NKG2D-DAP10-CD3 3 -expressing NK cells were observed to markedly increase NKG2D surface expression in NK cells and improve antitumor activity in a mouse model of OS (72). Although the number of studies concerning NK cell-based immunotherapy for OS has been few to the best of our knowledge, NK cell-based immunotherapy may hold significant promise for OS treatment. For future clinical applications, combination with other therapies, and genetic modification may provide increased benefit for cancer patients.

\section{Vaccines}

The aim of vaccination is to deliver intensified exposure of various tumor-associated factors to the immune system, with the hope of inducing an antitumor immune response in the form of an antibody and T-cell response that ultimately translates to clinical benefit. These 'tumor-associated 
factors' generally consist of autologous or allogeneic tumor cells, autologous dendritic cells, isolated tumor peptides or proteins, genetic material or other immunogenic substances, including heat shock proteins and gangliosides (73). In order to intensify the immune response, vaccines may be combined with costimulatory adjuvants, as well as immunostimulants, including IL-2 and GM-CSF.

In a phase I/II trial, recurrent or metastatic sarcoma patients were administered a subcutaneous injection of irradiated autologous tumor cells, accompanied by adjuvant IFN- $\alpha$ or GM-CSF (73). Delayed-type hypersensitivity (DTH) tests on irradiated tumor cells were negative in 20 patients tested at baseline, however, the test results converted to positive following 3 weekly vaccinations in $8 / 16$ patients who were retested. The median survival time for the $8 \mathrm{DTH}$ convertees was 16.6 months vs. 8.2 months for the 8 responders whose tumor DTH test remained negative (73). Dendritic cell vaccines are prepared by isolating and expanding the autologous dendritic cell population of patients ex vivo. The dendritic cells are then exposed to tumor-derived antigens, such as tumor lysate, peptides or genetic material, which may result in tumor-specific CTL responses and cytokine production. Mackall et al (74) used dendritic cells exposed to tumor-specific peptides, derived from fusion proteins and ET (a peptide known to bind HLA-A2), to treat pediatric patients exhibiting recurrent Ewing's sarcoma or rhabdomyosarcoma. The results of this study suggested that 5-year overall survival was improved in the group of patients who received vaccination, compared with those undergoing leukapheresis but not receiving vaccination (74). In a vaccination trial that combined external beam radiation therapy with intratumoral injection of dendritic cells as a neoadjuvant treatment for high-risk soft tissue sarcoma patients, 9/17 patients developed tumor-specific immune responses and 12/17 patients remained progression-free 1 year later (75). In a study performed by Suminoe et al (76), 5 children exhibiting refractory solid tumors (Ewing's sarcoma, synovial sarcoma or neuroblastoma) received dendritic cells (DCs) exposed to tumor lysate or tumor-specific synthetic peptides, consisting of SYT-SSX2 and EWS-Friend leukemia integration 1 transcription factor (FLI-1). A patient exhibiting Ewing's sarcoma, who received DCs pulsed with EWS-FLI-1-associated synthetic peptides, demonstrated total remission that was maintained for 77 months. An additional 2 patients exhibiting synovial sarcoma or neuroblastoma demonstrated temporary stabilization of disease (76). An alternative approach is to use vaccines consisting of peptide alone. A trial has been published reporting that 105AD7, a human monoclonal antibody that mimics the complement regulatory protein CD55 that is frequently overexpressed in OS, was well-tolerated in younger patients exhibiting OS, and was capable of inducing a T-cell proliferation response and antigen-specific IFN- $\gamma$ secretion (77). In a similar study utilizing SYT-SSX-derived peptide vaccines in patients exhibiting advanced synovial sarcoma, the administration of vaccine with incomplete Freund's adjuvant led to improved stable disease in patients, compared with those treated with vaccine alone (78). In order to enhance clinical efficacy, combination therapy with DC vaccine and IL-2 encapsulating polymeric micelles against EG7 tumor-bearing mice was examined (79). This treatment induced efficient accumulation of antigen-specific cytotoxic T-lymphocytes (CTLs) in the tumor and resulted in marked antitumor effects. The response of this combination therapy is encouraging and requires additional investigation for the treatment of OS (79).

\section{Immunologic checkpoint blockade}

CTL antigen-4 (A-4) is a potent immunoregulatory molecule that is capable of attenuating antitumor responses via downregulation of T-cell activation, thus inducing the occurrence of cancer (80). Ipilimumab is an antagonistic monoclonal antibody that blocks CTLA-4, and enhances antitumor immunity by inhibition of the immunosuppressive activity of regulatory T-cells (81). In a randomized, double-blind, phase II trial, patients exhibiting advanced melanoma were randomly assigned a fixed dose of ipilimumab of 10, 3, or $0.3 \mathrm{mg} / \mathrm{kg}$ every 3 weeks for 4 cycles, followed by maintenance therapy every 3 months (82). Ipilimumab demonstrated a dose-dependent effect on efficacy and safety measures and suggested that additional studies at a dose of $10 \mathrm{mg} / \mathrm{kg}$ may be required (82). Another randomized phase III trial demonstrated improved overall survival rates in patients exhibiting previously untreated metastatic melanoma, who were treated with CTLA-4 antagonist ipilimumab with dacarbazine (83). However, for synovial sarcoma patients, despite high expression of cancer testis (CT) antigens, no clinical benefit and no evidence of anti-CT antigen serological responses was identified (84). Although a number of patients achieved long-term progression-free survival, the majority of patients demonstrated disease progression (84). Lesterhuis et al (85) demonstrated that ipilimumab is able to exert a synergistic effect in the treatment of cancer in combination with gemcitabine chemotherapy. The number of studies concerning ipilimumab for the treatment of OS has been few to the best of our knowledge; however, comprehensive data suggests that +49 G/A polymorphism of the CTLA-4 gene is associated with increased susceptibility to OS $(86,87)$. The results of the above-mentioned studies provide novel promising insight into the clinical benefits of this therapeutic approach for the treatment of OS.

PD-1 is a member of the CD28 receptor family and is expressed on activated T-cells (88). Evidence suggests that activation of the PD-1/PD-ligand (L)1 signaling pathway may attenuate the immune response due to a decrease in cytokine production and induction of T-lymphocyte anergy and apoptosis (89). The expression of PD-L1 has been associated with not only progression, but additionally poor prognosis of human cancer (5). Preclinical cancer models have suggested that interruption of PD1/PD-L1 interactions may lead to augmented T-cell proliferation and enhanced humoral immunity $(90,91)$. A study has demonstrated that $58 \%$ of soft-tissue sarcomas (STS) possessed intratumoral infiltration of PD1-positive lymphocytes, and $65 \%$ of STS cases expressed PD-L1, which may benefit from PD1 signaling pathway-targeted therapy (92). Phase I clinical trials have been undertaken using nivolumab (BMS-936558), an antibody that is able to specifically block PD-1, producing objective responses in patients exhibiting non-small-cell lung cancer, melanoma and renal-cell cancer; the adverse event 
profile does not appear to preclude its use (93-95). To the best of our knowledge, studies concerning PD-1 and OS remain limited.

However, data from Zheng et al (96) revealed that the percentages of PD-1 were significantly upregulated on peripheral CD4+ and CD8+ T-cells from OS patients, and patients exhibiting metastasis demonstrated a significantly increased level of PD-1 on CD4+ T-cells compared with those without metastasis. Therefore, based on evidence concerning the clinical significance and therapeutic potential of targeting PD-1 in human cancer, there is reason to believe that an anti-PD-1 antibody may be a potential therapeutic strategy for the treatment of OS.

\section{Oncolytic virotherapy}

Oncolytic virotherapy is an emerging treatment approach, which utilizes replication-competent viruses in order to selectively infect and damage cancerous tissues, without causing harm to normal tissues (7). Advances in the past two decades in genetic engineering technologies, as well as viral delivery systems, have rapidly increased the pace of the clinical development of DNA and RNA virus therapies in cancer patients. A variety of clinical trials utilizing oncolytic viruses are currently being performed in OS patients.

Adenoviruses (AdV) are DNA viruses that are typically capable of causing mild respiratory, alimentary and conjunctiva tract infections (97). Adenovirus infection occurs via receptor-mediated endocytosis and release of double stranded DNA into the nucleus (98). Once the viral genome enters the nucleus, early-region $1 \mathrm{~A}(\mathrm{E} 1 \mathrm{~A})$ or early-region 1B (E1B) gene transcription begins $(99,100)$. The products of these genes bind a number of cellular proteins, including the retinoblastoma and p53 proteins $(99,100)$. This interaction inactivates these cellular proteins, inducing cell cycle progression and promotion of DNA replication (99). Thus, deletions in E1A or E1B genes result in attenuated mutants that are unable to bind normal cellular proteins, which was expected to replicate only in tumor cells and to prevent viral replication in non-cancerous cells. Mutant adenovirus $d l 1520$ (also known as ONYX-015 and CI-1042) contains a deletion in the E1B gene that does not express a functional E1B $55 \mathrm{kD}$ protein. Due to this mutation, $d l 1520$ was expected to replicate in and lyse p53-deficient human tumor cells, and not damage cells possessing functional p53 (101). This agent has been administered intratumorally to patients exhibiting recurrent head and neck cancer (102). Results have demonstrated that intratumoral administration of $d l 1520$ is feasible, well-tolerated and associated with biological activity (102). In OS, inactivating p53 mutations are common (103), and the investigation of AdV, particularly with a deletion of the E1B gene for the treatment of OS, is warranted. The conditionally replicating AdV vectors (CRAd) AdDelta24 possess small deletions in conserver region-2 of $\mathrm{E} 1 \mathrm{~A}$, which prohibit the E1A viral protein from binding to $\mathrm{Rb}$, and subsequently inactivate cell progression from the $\mathrm{G}_{1}$ to the $\mathrm{S}$ (DNA synthesis) phase of mitosis, as well as causing replication in and lysis of cancer cells with significant efficiency (104). As genetic alterations in the $\mathrm{Rb}$ pathway are frequently observed in OS, the oncolytic capacity of the CRAd AdDelta24 was investigated in primary OS cells in vitro and in vivo (105). AdDelta24 was demonstrated to be markedly active in the killing of human OS cell lines, as well as primary cell cultures. Furthermore, intratumoral injections of AdDelta24 into established human OS xenografts led to a significant tumor growth delay (105). Moreover, AdDelta $\Delta 24-$ RGD OS treatment induced antitumor activity in vitro, which was additionally enhanced when combined with cisplatin treatment (106). In addition, E1A, E1B double-restricted replicating adenovirus significantly replicated in and led to oncolysis of tumors in vitro and in vivo, without marked toxicity to normal cells, suggesting a potential use of this combination therapy for the treatment of OS $(107,108)$. Another method of introducing therapeutic genes into malignant cells in vivo may provide an effective treatment strategy for OS. AdV-osteocalcin (OC)-E1A, which contains a murine OC promoter for regulation of the production of adenoviral E1A, allows for restricted viral replication and subsequent lysis of tumor cells, and has demonstrated efficacy in preclinical models of OS and its pulmonary metastasis $(109,110)$. Human telomerase and the catalytic subunit telomerase reverse transcriptase (hTERT), a polymerase that stabilizes telomere lengths, are activated in a significant number of human cancer types, however, are not activated in normal tissues $(111,112)$. Li et al (113) developed a replication-defective oncolytic adenovirus that utilizes hTERT promoter to control the expression of E1A and E1B genes, which are associated with an internal ribosome entry site. This agent has been evaluated in human OS in vitro and in vivo, and provides a promising strategy for the treatment of human OS. Inhibitor of growth family, member 4 (ING4) is a novel member of the ING family that demonstrates potential tumor-suppressive effects via multiple signaling pathways (114). Adenovirus-mediated ING4 gene transfer in human OS significantly suppressed tumor growth in vitro and in vivo (115). This agent was associated with an increase in the expression of cell cycle-associated molecules p 21 and p27, and a decrease in the ratio of anti- to pro-apoptotic molecules B-cell lymphoma-2 (Bcl-2)/Bcl-2-associated X protein, followed by the activation of caspase- 3 which resulted in apoptosis via intrinsic apoptotic signaling pathways, and the inhibition of tumor angiogenesis (114).

Herpes simplex virus (HSV) is a neurotropic virus that possesses a large linear, double-stranded DNA genome, which is presented in the form of two distinct serotypes: HSV-1 and HSV-2 (116). HSV often infects the mucosa of the mouth, eyes and the human anogenital tract (117). The natural infection of HSV may activate double stranded RNA-dependent protein kinase (PKR) to phosphorylate the eukaryotic initiation factor (eIF)-4A, and subsequently terminate host protein synthesis in order to prevent viral replication (118). Virus gene $\gamma-34.5$ is the primary neuropathogenicity gene in HSV, and its protein product [infected cell protein(ICP)-34.5)] causes dephosphorylation of eIF-2 and disinhibition of protein synthesis (118). The Ras/mitogen-activated protein kinase signaling pathway is frequently activated in cancer cells, which suppresses PKR and enables $\gamma$-34.5-deficient HSV to replicate selectively in cancer cells (119). In addition, the ICP-6 gene encodes the large subunit of ribonucleotide reductase, which is essential for the replication of viral DNA and is highly expressed in rapidly dividing tumor 
cells (117). ICP-6-mutated HSV is only able to replicate in rapidly dividing cells, but not in quiescent cells (117). Thus, ICP-6/ $\gamma$-34.5-deleted HSV imposes oncolytic activity in tumor tissue and low pathogenicity in normal tissues (117). NV1020 is an attenuated, replication-competent, recombinant virus that is derived from HSV-1 (120). NV1020 was attenuated by deletion of a $15-\mathrm{kb}$ region at the UL/S junction and a $700 \mathrm{bp}$ deletion in the thymidine kinase locus (120). G207 is another conditionally replicating HSV-1 vector exhibiting viral gene deletions of two copies of the $\gamma-34.5$ and insertion of an Escherichia coli LacZ (121). NV1020 and G207 demonstrated that rhabdomyosarcoma, malignant fibrous histiocytoma and OS were sensitive to HSV recombinants and may benefit from this treatment $(122,123)$. Vaccinia virus treatment has additionally been investigated in OS. GLV-1h68 is a recombinant, replication-competent vaccinia virus that has been demonstrated to exert oncolytic effects against human bone and soft-tissue sarcoma cell lines in vitro and in vivo, including in OS (118).

\section{Conclusion}

There have been multiple preclinical and clinical trials evaluating the role of immunotherapy in OS; the clinical activity in certain patients has demonstrated that this may be an area deserving additional study. However, the field of immunotherapy has not yet matured enough to demonstrate decisive and robust antitumor effects. Therefore, surgery remains the primary choice for removal of tumors, and multiagent chemotherapy may be utilized for the treatment of any remaining or micrometastatic lesions. Nonspecific immunomodulation, with the use of L-MTP-PE, IFNs, GM-CSF and IL-2, has demonstrated a significant survival benefit. In order to achieve the desired overall survival rates, immunomodulation combined with conventional chemotherapy treatment is recommended. With regard to adoptive T-cell immunotherapy, enhancing T-cell expansion and persistence in vivo, overcoming tumor-mediated immunosuppression, improving homing to tumor sites and improving the safety of T-cell therapy may lead to a more successful approach for the treatment of OS (39). To the best of our knowledge, the number of published trials utilizing vaccines for the treatment of OS is low. However, there are a number of pieces of evidence demonstrating the application of vaccines for the treatment of sarcoma (124). The investigation of surface antigens and cancer testis antigen may provide potential targets for vaccine development (6). As an immunological checkpoint, understanding the mechanism of CTLA-4 and PD-1 blockade and determining its applicability to the treatment of OS remains to be elucidated. The future of oncolytic viruses in the treatment of OS will depend on more successful viral delivery, tumor penetration and replication strategies. In addition, harnessing the host immune system to aid in viral killing and specific targeting of resistant cancer stem cells, which are believed to be cells that possess the ability to self-renew and give rise to other tumor cells, is important (118). There are a variety of targeted agents that have demonstrated antitumor activity in vitro and in vivo. In summary, an improved knowledge and understanding of the immune system may lead to the development of more potent approaches for the treatment of OS. It is important to promote the development of immunotherapeutic strategies for the treatment of OS, particularly in metastatic OS, where a standard systemic therapy is not available. The increasing efforts in immunotherapy studies with a particular focus in overcoming heterogeneity are encouraging, thus hold promise for the successful treatment of patients with OS.

\section{References}

1. Sakamoto A and Iwamoto Y: Current status and perspectives regarding the treatment of osteo-sarcoma: Chemotherapy. Rev Recent Clin Trials 3: 228-231, 2008.

2. Mori K, Rédini F, Gouin F, Cherrier B and Heymann D: Osteosarcoma: Current status of immunotherapy and future trends (Review). Oncol Rep 15: 693-700, 2006.

3. Loeb DM: Is there a role for immunotherapy in osteosarcoma? Cancer Treat Res 152: 447-457, 2009.

4. Habel N, Hamidouche Z, Girault I, Patiño-García A, Lecanda F, Marie PJ and Fromigué O: Zinc chelation: A metallothionein 2A's mechanism of action involved in osteosarcoma cell death and chemotherapy resistance. Cell Death Dis 4: e874, 2013.

5. Wilky BA and Goldberg JM: Immunotherapy in sarcoma: A new frontier. Discov Med 17: 201-206, 2014.

6. D'Angelo SP, Tap WD, Schwartz GK and Carvajal RD: Sarcoma immunotherapy: Past approaches and future directions. Sarcoma 2014: 391967, 2014.

7. Russell SJ, Peng KW and Bell JC: Oncolytic virotherapy. Nat Biotechnol 30: 658-670, 2012.

8. Dzierzbicka K, Gozdowska M and Kołodziejczyk AM: L-MTP-PE - a potential antineoplastic agent. Postepy Hig Med Dosw 51: 227-236, 1997 (In Polish).

9. Kager L, Pötschger U and Bielack S: Review of mifamurtide in the treatment of patients with osteosarcoma. Ther Clin Risk Manag 6: 279-286, 2010.

10. MacEwen EG, Kurzman ID, Rosenthal RC, Smith BW, Manley PA, Roush JK and Howard PE: Therapy for osteosarcoma in dogs with intravenous injection of liposome-encapsulated muramyl tripeptide. J Natl Cancer Inst 81: 935-938, 1989.

11. Kleinerman ES, Gano JB, Johnston DA, Benjamin RS and Jaffe N: Efficacy of liposomal muramyl tripeptide (CGP 19835A) in the treatment of relapsed osteosarcoma. Am J Clin Oncol 18: 93-99, 1995.

12. Kleinerman ES, Meyers PA, Raymond AK, Gano JB, Jia SF and Jaffe N: Combination therapy with ifosfamide and liposome-encapsulated muramyl tripeptide: Tolerability, toxicity and immune stimulation. J Immunother Emphasis Tumor Immunol 17: 181-193, 1995.

13. Meyers PA, Schwartz CL, Krailo M, Kleinerman ES, Betcher D, Bernstein ML, Conrad E, Ferguson W, Gebhardt M, Goorin AM, et al: Osteosarcoma: A randomized, prospective trial of the addition of ifosfamide and/or muramyl tripeptide to cisplatin, doxorubicin, and high-dose methotrexate. J Clin Oncol 23: 2004-2011, 2005.

14. Meyers PA, Schwartz CL, Krailo MD, Healey JH, Bernstein ML, Betcher D, Ferguson WS, Gebhardt MC, Goorin AM, Harris M, et al: Osteosarcoma: The addition of muramyl tripeptide to chemotherapy improves overall survival - a report from the Children's Oncology Group. J Clin Oncol 26: 633-638, 2008.

15. Chou AJ, Kleinerman ES, Krailo MD, Chen Z, Betcher DL, Healey JH, Conrad EU 3rd, Nieder ML, Weiner MA, Wells RJ, et al: Addition of muramyl tripeptide to chemotherapy for patients with newly diagnosed metastatic osteosarcoma: A report from the Children's Oncology Group. Cancer 115: 5339-5348, 2009.

16. Anderson PM, Meyers P, Kleinerman E, Venkatakrishnan K, Hughes DP, Herzog C, Huh W, Sutphin R, Vyas YM, Shen V, et al: Mifamurtide in metastatic and recurrent osteosarcoma: A patient access study with pharmacokinetic, pharmacodynamic, and safety assessments. Pediatr Blood Cancer 61: 238-244, 2014.

17. Pahl JH, Kwappenberg KM, Varypataki EM, Santos SJ, Kuijjer ML, Mohamed S, Wijnen JT, van Tol MJ, Cleton-Jansen AM, Egeler RM, et al: Macrophages inhibit human osteosarcoma cell growth after activation with the bacterial cell wall derivative liposomal muramyl tripeptide in combination with interferon- $\gamma$. J Exp Clin Cancer Res 33: 27, 2014. 
18. Song HJ, Lee EK, Lee JA, Kim HL and Jang KW: The addition of mifamurtide to chemotherapy improves lifetime effectiveness in children with osteosarcoma: A Markov model analysis. Tumour Biol 35: 8771-8779, 2014.

19. Lindner DJ: Interferons as antiangiogenic agents. Curr Oncol Rep 4: 510-514, 2002.

20. Whelan J, Patterson D, Perisoglou M, Bielack S, Marina N, Smeland $\mathrm{S}$ and Bernstein $\mathrm{M}$ : The role of interferons in the treatment of osteosarcoma. Pediatr Blood Cancer 54: 350-354, 2010.

21. Müller CR, Smeland S, Bauer HC, Saeter G and Strander H: Interferon-alpha as the only adjuvant treatment in high-grade osteosarcoma: Long term results of the Karolinska Hospital series. Acta Oncol 44: 475-480, 2005.

22. Strander H and Einhorn S: Effect of human leukocyte interferon on the growth of human osteosarcoma cells in tissue culture. Int J Cancer 19: 468-473, 1977.

23. Brosjö O, Bauer HC, Broström LA, Nilsonne U, Nilsson OS, Reinholt FP, Strander H and Tribukait B: Influence of human alpha-interferon on four human osteosarcoma xenografts in nude mice. Cancer Res 45: 5598-5602, 1985.

24. Manara MC, Serra M, Benini S, Picci P and Scotlandi K: Effectiveness of Type I interferons in the treatment of multidrug resistant osteosarcoma cells. Int J Oncol 24: 365-372, 2004.

25. Strander H, Bauer HC, Brosjö O, Fernberg JO, Kreicbergs A, Nilsonne U, Silfverswärd C, Signomklao T and Söderlund V: Long-term adjuvant interferon treatment of human osteosarcoma. A pilot study. Acta Oncol 34: 877-880, 1995.

26. Bukowski R, Ernstoff MS, Gore ME, Nemunaitis JJ, Amato R, Gupta SK and Tendler CL: Pegylated interferon alfa-2b treatment for patients with solid tumors: A phase I/II study. J Clin Oncol 20: 3841-3849, 2002.

27. Bukowski RM, Tendler C, Cutler D, Rose E, Laughlin MM and Statkevich P: Treating cancer with PEG Intron: Pharmacokinetic profile and dosing guidelines for an improved interferon-alpha-2b formulation. Cancer 95: 389-396, 2002.

28. Postiglione L, Di Domenico G, Giordano-Lanza G, Ladogana P, Turano M, Castaldo C, Di Meglio F, Cocozza S and Montagnani S: Effect of human granulocyte macrophage-colony stimulating factor on differentiation and apoptosis of the human osteosarcoma cell line SaOS-2. Eur J Histochem 47: 309-316, 2003.

29. Anderson PM, Markovic SN, Sloan JA, Clawson ML, Wylam M, Arndt CA, Smithson WA, Burch P, Gornet M and Rahman E: Aerosol granulocyte macrophage-colony stimulating factor: A low toxicity, lung-specific biological therapy in patients with lung metastases. Clin Cancer Res 5: 2316-2323, 1999.

30. Arndt CA, Koshkina NV, Inwards CY, et al: Inhaled granulocyte-macrophage colony stimulating factor for first pulmonary recurrence of osteosarcoma: Effects on disease-free survival and immunomodulation. A report from the Children's Oncology Group. Clin Cancer Res 16: 4024-4030, 2010.

31. Du T, Shi G, Li YM, Zhang JF, Tian HW, Wei YQ, Deng H and Yu DC: Tumor-specific oncolytic adenoviruses expressing granulocyte macrophage colony-stimulating factor or anti-CTLA4 antibody for the treatment of cancers. Cancer Gene Ther 21: 340-348, 2014.

32. Schwinger W, Klass V, Benesch M, Lackner H, Dornbusch HJ, Sovinz P, Moser A, Schwantzer G and Urban C: Feasibility of high-dose interleukin-2 in heavily pretreated pediatric cancer patients. Ann Oncol 16: 1199-1206, 2005.

33. Luksch R, Perotti D, Cefalo G, Gambacorti Passerini C, Massimino M, Spreafico F, Casanova M, Ferrari A, Terenziani M, Polastri D, et al: Immunomodulation in a treatment program including pre- and post-operative interleukin-2 and chemotherapy for childhood osteosarcoma. Tumori 89: 263-268, 2003 .

34. Guma SR, Lee DA, Ling Y, Gordon N and Kleinerman ES: Aerosol interleukin-2 induces natural killer cell proliferation in the lung and combination therapy improves the survival of mice with osteosarcoma lung metastasis. Pediatr Blood Cancer 61: 1362-1368, 2014

35. Guma SR, Lee DA, Yu L, Gordon N, Hughes D, Stewart J, Wang WL and Kleinerman ES: Natural killer cell therapy and aerosol interleukin-2 for the treatment of osteosarcoma lung metastasis. Pediatr Blood Cancer 61: 618-626, 2014.

36. Kohyama K, Sugiura H, Kozawa E, Wasa J, Yamada K, Nishioka A, Kamei Y and Taguchi O: Antitumor activity of an interleukin-2 monoclonal antibody in a murine osteosarcoma transplantation model. Anticancer Res 32: 779-782, 2012.
37. Dow S, Elmslie R, Kurzman I, MacEwen G, Pericle F and Liggitt D: Phase I study of liposome-DNA complexes encoding the interleukin-2 gene in dogs with osteosarcoma lung metastases. Hum Gene Ther 16: 937-946, 2005.

38. Rosenberg SA, Restifo NP, Yang JC, Morgan RA and Dudley ME: Adoptive cell transfer: A clinical path to effective cancer immunotherapy. Nat Rev Cancer 8: 299-308, 2008.

39. DeRenzo C and Gottschalk S: Genetically modified T-cell therapy for osteosarcoma. Adv Exp Med Biol 804: 323-340, 2014.

40. Ruella M and Kalos M: Adoptive immunotherapy for cancer. Immunol Rev 257: 14-38, 2014

41. Restifo NP, Dudley ME and Rosenberg SA: Adoptive immunotherapy for cancer: Harnessing the T cell response. Nat Rev Immunol 12: 269-281, 2012

42. Morgan RA, Dudley ME, Wunderlich JR, Hughes MS, Yang JC, Sherry RM, Royal RE, Topalian SL, Kammula US, Restifo NP, et al: Cancer regression in patients after transfer of genetically engineered lymphocytes. Science 314: 126-129, 2006.

43. Johnson LA, Morgan RA, Dudley ME, Cassard L, Yang JC, Hughes MS, Kammula US, Royal RE, Sherry RM, Wunderlich JR, et al: Gene therapy with human and mouse T-cell receptors mediates cancer regression and targets normal tissues expressing cognate antigen. Blood 114: 535-546, 2009.

44. Rosenberg SA: Cell transfer immunotherapy for metastatic solid cancer - what clinicians need to know. Nat Rev Clin Oncol 8: 577-585, 2011

45. Robbins PF, Morgan RA, Feldman SA, Yang JC, Sherry RM, Dudley ME, Wunderlich JR, Nahvi AV, Helman LJ, Mackall CL, et al: Tumor regression in patients with metastatic synovial cell sarcoma and melanoma using genetically engineered lymphocytes reactive with NY-ESO-1. J Clin Oncol 29: 917-924, 2011.

46. Morgan RA, Chinnasamy N, Abate-Daga D, Gros A, Robbins PF, Zheng Z, Dudley ME, Feldman SA, Yang JC, Sherry RM, et al: Cancer regression and neurological toxicity following anti-MAGE-A3 TCR gene therapy. J Immunother 36: 133-151, 2013.

47. Linette GP, Stadtmauer EA, Maus MV, Rapoport AP, Levine BL, Emery L, Litzky L, Bagg A, Carreno BM, Cimino PJ, et al: Cardiovascular toxicity and titin cross-reactivity of affinity-enhanced T cells in myeloma and melanoma. Blood 122: 863-871, 2013.

48. Parkhurst MR, Yang JC, Langan RC, Dudley ME, Nathan DA, Feldman SA, Davis JL, Morgan RA, Merino MJ, Sherry RM, et al: $T$ cells targeting carcinoembryonic antigen can mediate regression of metastatic colorectal cancer but induce severe transient colitis. Mol Ther 19: 620-626, 2011.

49. Song DG, Ye Q, Poussin M, Harms GM, Figini M and Powell DJ Jr: CD27 costimulation augments the survival and antitumor activity of redirected human T cells in vivo. Blood 119: 696-706, 2012.

50. Maher J, Brentjens RJ, Gunset G, Rivière I and Sadelain M: Human T-lymphocyte cytotoxicity and proliferation directed by a single chimeric TCRzeta/CD28 receptor. Nat Biotechnol 20: 70-75, 2002.

51. Altvater B, Landmeier S, Pscherer S, Temme J, Juergens H, Pule M and Rossig C: 2B4 (CD244) signaling via chimeric receptors costimulates tumor-antigen specific proliferation and in vitro expansion of human T cells. Cancer Immunol Immunother 58: 1991-2001, 2009.

52. Song DG, Ye Q, Carpenito C, Poussin M, Wang LP, Ji C, Figini M, June $\mathrm{CH}$, Coukos $\mathrm{G}$ and Powell DJ Jr: In vivo persistence, tumor localization, and antitumor activity of CAR-engineered T cells is enhanced by costimulatory signaling through CD137 (4-1BB). Cancer Res 71: 4617-4627, 2011.

53. Hombach AA, Heiders J, Foppe M, Chmielewski M and Abken H: OX40 costimulation by a chimeric antigen receptor abrogates CD28 and IL-2 induced IL-10 secretion by redirected CD4(+) T cells. Oncoimmunology 1: 458-466, 2012.

54. Vitale M, Pelusi G, Taroni B, Gobbi G, Micheloni C, Rezzani R, Donato F, Wang X and Ferrone S: HLA class I antigen down-regulation in primary ovary carcinoma lesions: Association with disease stage. Clin Cancer Res 11: 67-72, 2005.

55. Morris CD, Gorlick R, Huvos G, Heller G, Meyers PA and Healey JH: Human epidermal growth factor receptor 2 as a prognostic indicator in osteogenic sarcoma. Clin Orthop Relat Res 382: 59-65, 2001.

56. Ahmed N, Salsman VS, Yvon E, Louis CU, Perlaky L, Wels WS, Dishop MK, Kleinerman EE, Pule M, Rooney CM, et al: Immunotherapy for osteosarcoma: Genetic modification of $\mathrm{T}$ cells overcomes low levels of tumor antigen expression. Mol Ther 17: 1779-1787, 2009. 
57. Rainusso N, Brawley VS, Ghazi A, Hicks MJ, Gottschalk S, Rosen JM and Ahmed N: Immunotherapy targeting HER2 with genetically modified $\mathrm{T}$ cells eliminates tumor-initiating cells in osteosarcoma. Cancer Gene Ther 19: 212-217, 2012.

58. Morgan RA, Yang JC, Kitano M, Dudley ME, Laurencot CM and Rosenberg SA: Case report of a serious adverse event following the administration of $\mathrm{T}$ cells transduced with a chimeric antigen receptor recognizing ERBB2. Mol Ther 18: 843-851, 2010.

59. Huang G, Yu L, Cooper LJ, Hollomon M, Huls $\mathrm{H}$ and Kleinerman ES: Genetically modified T cells targeting interleukin-11 receptor $\alpha$-chain kill human osteosarcoma cells and induce the regression of established osteosarcoma lung metastases. Cancer Res 72: 271-281, 2012.

60. Kiessling S, Muller-Newen G, Leeb SN, Hausmann M, Rath HC, Strater J, Spottl T, Schlottmann K, Grossmann J, Montero-Julian FA, et al: Functional expression of the interleukin-11 receptor alpha-chain and evidence of antiapoptotic effects in human colonic epithelial cells. J Biol Chem 279: 10304-10315, 2004

61. John LB, Devaud C, Duong CP, Yong CS, Beavis PA, Haynes NM, Chow MT, Smyth MJ, Kershaw MH and Darcy PK: Anti-PD-1 antibody therapy potently enhances the eradication of established tumors by gene-modified T cells. Clin Cancer Res 19: 5636-5646, 2013.

62. Raulet DH and Guerra N: Oncogenic stress sensed by the immune system: Role of natural killer cell receptors. Nat Rev Immunol 9: 568-580, 2009.

63. Ljunggren HG and Kärre K: In search of the 'missing self': MHC molecules and NK cell recognition. Immunol Today 11: 237-244, 1990

64. Markiewicz K, Zeman K, Kozar A, Gołębiowska-Wawrzyniak M and Woźniak W: Evaluation of selected parameters of cellular immunity in children with osteosarcoma at diagnosis. Med Wieku Rozwoj 16: 212-221, 2012.

65. Moore C, Eslin D, Levy A, Roberson J, Giusti V and Sutphin R: Prognostic significance of early lymphocyte recovery in pediatric osteosarcoma. Pediatr Blood Cancer 55: 1096-1102, 2010.

66. Delgado D, Webster DE, DeSantes KB, Durkin ET and Shaaban AF: KIR receptor-ligand incompatibility predicts killing of osteosarcoma cell lines by allogeneic NK cells. Pediatr Blood Cancer 55: 1300-1305, 2010.

67. Tsukahara T, Kawaguchi S, Torigoe T, Asanuma H, Nakazawa E, Shimozawa K, Nabeta Y, Kimura S, Kaya M, Nagoya S, et al: Prognostic significance of HLA class I expression in osteosarcoma defined by anti-pan HLA class I monoclonal antibody, EMR8-5. Cancer Sci 97: 1374-1380, 2006.

68. Cho D, Shook DR, Shimasaki N, Chang YH, Fujisaki H and Campana D: Cytotoxicity of activated natural killer cells against pediatric solid tumors. Clin Cancer Res 16: 3901-3909, 2010.

69. Pahl JH, Ruslan SE, Buddingh EP, et al: Anti-EGFR antibody cetuximab enhances the cytolytic activity of natural killer cells toward osteosarcoma. Clin Cancer Res 18: 432-441, 2012.

70. Tam YK, Martinson JA, Doligosa K and Klingemann HG: Ex vivo expansion of the highly cytotoxic human natural killer-92 cell-line under current good manufacturing practice conditions for clinical adoptive cellular immunotherapy. Cytotherapy 5: 259-272, 2003.

71. Tonn T, Schwabe D, Klingemann HG, Becker S, Esser R, Koehl U, Suttorp M, Seifried E, Ottmann OG and Bug G: Treatment of patients with advanced cancer with the natural killer cell line NK-92. Cytotherapy 15: 1563-1570, 2013.

72. Chang YH, Connolly J, Shimasaki N, Mimura K, Kono K and Campana D: A chimeric receptor with NKG2D specificity enhances natural killer cell activation and killing of tumor cells. Cancer Res 73: 1777-1786, 2013.

73. Dillman R, Barth N, Selvan S, Beutel L, de Leon C, DePriest C, Peterson $C$ and Nayak S: Phase I/II trial of autologous tumor cell line-derived vaccines for recurrent or metastatic sarcomas. Cancer Biother Radiopharm 19: 581-588, 2004.

74. Mackall CL, Rhee EH, Read EJ, et al: A pilot study of consolidative immunotherapy in patients with high-risk pediatric sarcomas. Clin Cancer Res 14: 4850-4858, 2008.

75. Finkelstein SE, Iclozan C, Bui MM, Cotter MJ, Ramakrishnan R, Ahmed J, Noyes DR, Cheong D, Gonzalez RJ, Heysek RV, et al: Combination of external beam radiotherapy (EBRT) with intratumoral injection of dendritic cells as neo-adjuvant treatment of high-risk soft tissue sarcoma patients. Int J Radiat Oncol Biol Phys 82: 924-932, 2012.
76. Suminoe A, Matsuzaki A, Hattori H, Koga Y and Hara T: Immunotherapy with autologous dendritic cells and tumor antigens for children with refractory malignant solid tumors. Pediatr Transplant 6: 746-753, 2009.

77. Pritchard-Jones K, Spendlove I, Wilton C, Whelan J, Weeden S, Lewis I, Hale J, Douglas C, Pagonis C, Campbell B, et al: Immune responses to the 105AD7 human anti-idiotypic vaccine after intensive chemotherapy, for osteosarcoma. Br J Cancer 92: $1358-1365,2005$

78. Kawaguchi S, Tsukahara T, Ida K, Kimura S, Murase M, Kano M, Emori M, Nagoya S, Kaya M, Torigoe T, et al: SYT-SSX breakpoint peptide vaccines in patients with synovial sarcoma: A study from the Japanese Musculoskeletal Oncology Group. Cancer Sci 103: 1625-1630, 2012.

79. Miki K, Nagaoka K, Harada M, Hayashi T, Jinguji H, Kato Y and Maekawa R: Combination therapy with dendritic cell vaccine and IL-2 encapsulating polymeric micelles enhances intra-tumoral accumulation of antigen-specific CTLs. Int Immunopharmacol 23: 499-504, 2014.

80. Liu S, Geng P, Cai X and Wang J: Comprehensive evaluation of the cytotoxic T-lymphocyte antigen- 4 gene polymorphisms in risk of bone sarcoma. Genet Test Mol Biomarkers 18: 574-579, 2014.

81. Yano H, Thakur A, Tomaszewski EN, Choi M, Deol A and Lum LG: Ipilimumab augments antitumor activity of bispecific antibody-armed T cells. J Transl Med 12: 191, 2014.

82. Wolchok JD, Neyns B, Linette G, Negrier S, Lutzky J, Thomas L, Waterfield W, Schadendorf D, Smylie M, Guthrie T Jr, et al: Ipilimumab monotherapy in patients with pretreated advanced melanoma: A randomised, double-blind, multicentre, phase 2, dose-ranging study. Lancet Oncol 11: 155-164, 2010.

83. Robert C, Thomas L, Bondarenko I, O'Day S, Weber J, Garbe C, Lebbe C, Baurain JF, Testori A, Grob JJ, et al: Ipilimumab plus dacarbazine for previously untreated metastatic melanoma. N Engl J Med 364: 2517-2526, 2011.

84. Maki RG, Jungbluth AA, Gnjatic S, Schwartz GK, D'Adamo DR, Keohan ML, Wagner MJ, Scheu K, Chiu R, Ritter E, et al: A pilot study of anti-CTLA4 antibody ipilimumab in patients with synovial sarcoma. Sarcoma 2013: 168145, 2013.

85. Lesterhuis WJ, Salmons J, Nowak AK, Rozali EN, Khong A, Dick IM, Harken JA, Robinson BW and Lake RA: Synergistic effect of CTLA-4 blockade and cancer chemotherapy in the induction of anti-tumor immunity. PLoS One 8: e61895, 2013.

86. Wang W, Wang J, Song H, Liu J, Song B and Cao X: Cytotoxic T-lymphocyte antigen- $4+49 \mathrm{G} / \mathrm{A}$ polymorphism is associated with increased risk of osteosarcoma. Genet Test Mol Biomarkers 15: 503-506, 2011.

87. Liu Y, He Z, Feng D, Shi G, Gao R, Wu X, Song W and Yuan W: Cytotoxic T-lymphocyte antigen-4 polymorphisms and susceptibility to osteosarcoma. DNA Cell Biol 30: 1051-1055, 2011

88. Sznol M and Chen L: Antagonist antibodies to PD-1 and B7-H1 (PD-L1) in the treatment of advanced human cancer. Clin Cancer Res 19: 1021-1034, 2013.

89. Kline J and Gajewski TF: Clinical development of mAbs to block the PD1 pathway as an immunotherapy for cancer. Curr Opin Investig Drugs 11: 1354-1359, 2010.

90. Okudaira K, Hokari R, Tsuzuki Y, Okada Y, Komoto S, Watanabe C, Kurihara C, Kawaguchi A, Nagao S, Azuma M, et al: Blockade of B7-H1 or B7-DC induces an anti-tumor effect in a mouse pancreatic cancer model. Int J Oncol 35: 741-749, 2009.

91. Iwai Y, Terawaki S and Honjo T: PD-1 blockade inhibits hematogenous spread of poorly immunogenic tumor cells by enhanced recruitment of effector T cells. Int Immunol 17: 133-144, 2005.

92. Kim JR, Moon YJ, Kwon KS, Bae JS, Wagle S, Kim KM, Park HS, Lee H, Moon WS, Chung MJ, et al: Tumor infiltrating PD1-positive lymphocytes and the expression of PD-L1 predict poor prognosis of soft tissue sarcomas. PLoS One 8: e82870, 2013

93. Brahmer JR, Drake CG, Wollner I, Powderly JD, Picus J, Sharfman WH, Stankevich E, Pons A, Salay TM, McMiller TL, et al: Phase I study of single-agent anti-programmed death-1 (MDX-1106) in refractory solid tumors: Safety, clinical activity, pharmacodynamics and immunologic correlates. J Clin Oncol 28: 3167-3175, 2010.

94. Topalian SL, Hodi FS, Brahmer JR, Gettinger SN, Smith DC McDermott DF, Powderly JD, Carvajal RD, Sosman JA, Atkins MB, et al: Safety, activity and immune correlates of anti-PD-1 antibody in cancer. N Engl J Med 366: 2443-2454, 2012.

95. Hamid O, Robert C, Daud A, Hodi FS, Hwu WJ, Kefford R, Wolchok JD, Hersey P, Joseph RW, Weber JS, et al: Safety and tumor responses with lambrolizumab (anti-PD-1) in melanoma. N Engl J Med 369: 134-144, 2013. 
96.Zheng W, Xiao H, Liu H and Zhou Y: Expression of programmed death 1 is correlated with progression of osteosarcoma. APMIS 123: 102-107, 2015.

97.Lynch JP 3rd, Fishbein M and Echavarria M: Adenovirus. Semin Respir Crit Care Med 32: 494-511, 2011.

98. Tomko RP, Xu R and Philipson L: HCAR and MCAR: The human and mouse cellular receptors for subgroup $\mathrm{C}$ adenoviruses and group B coxsackieviruses. Proc Natl Acad Sci USA 94: 3352-3356, 1997.

99. Chu RL, Post DE, Khuri FR and Van Meir EG: Use of replicating oncolytic adenoviruses in combination therapy for cancer. Clin Cancer Res 10: 5299-5312, 2004.

100.Liu TC and Kirn D: Viruses with deletions in antiapoptotic genes as potential oncolytic agents. Oncogene 24: 6069-6079, 2005.

101.Bischoff JR, Kirn DH, Williams A, Heise C, Horn S, Muna M, Ng L, Nye JA, Sampson-Johannes A, Fattaey A and McCormick F: An adenovirus mutant that replicates selectively in p53-deficient human tumor cells. Science 274: 373-376, 1996.

102. Ganly I, Kirn D, Eckhardt G, Rodriguez GI, Soutar DS, Otto R, Robertson AG, Park O, Gulley ML, Heise C, et al: A phase I study of Onyx-015, an E1B attenuated adenovirus, administered intratumorally to patients with recurrent head and neck cancer. Clin Cancer Res 6: 798-806, 2000.

103. Miller CW, Aslo A, Tsay C, Slamon D, Ishizaki K, Toguchida J, Yamamuro T, Lampkin B and Koeffler HP: Frequency and structure of p53 rearrangements in human osteosarcoma. Cancer Res 50: 7950-7954, 1990.

104. Fueyo J, Gomez-Manzano C, Alemany R, Lee PS, McDonnell TJ, Mitlianga P, Shi YX, Levin VA, Yung WK and Kyritsis AP: A mutant oncolytic adenovirus targeting the $\mathrm{Rb}$ pathway produces anti-glioma effect in vivo. Oncogene 19: 2-12, 2000.

105. Witlox AM, Van Beusechem VW, Molenaar B, Bras H, Schaap GR, Alemany R, Curiel DT, Pinedo HM, Wuisman PI and Gerritsen WR: Conditionally replicative adenovirus with tropism expanded towards integrins inhibits osteosarcoma tumor growth in vitro and in vivo. Clin Cancer Res 10: 61-67, 2004.

106. Martinez-Velez N, Xipell E, Jauregui P, Zalacain M, Marrodan L, Zandueta C, Vera B, Urquiza L, Sierrasesúmaga L, Julián MS, et al: The oncolytic adenovirus $\Delta 24-$ RGD in combination with cisplatin exerts a potent anti-osteosarcoma activity. J Bone Miner Res 29: 2287-2296, 2014.

107. Fukuda K, Abei M, Ugai H, Seo E, Wakayama M, Murata T, Todoroki T, Tanaka N, Hamada H and Yokoyama KK: E1A, E1B double-restricted adenovirus for oncolytic gene therapy of gallbladder cancer. Cancer Res 63: 4434-4440, 2003.

108. Fukuda K, Abei M, Ugai H, Kawashima R, Seo E, Wakayama M, Murata T, Endo S, Hamada H, Hyodo I and Yokoyama KK: E1A, E1B double-restricted replicative adenovirus at low dose greatly augments tumor-specific suicide gene therapy for gallbladder cancer. Cancer Gene Ther 16: 126-136, 2009.

109. Benjamin R, Helman L, Meyers P and Reaman G: A phase I/II dose escalation and activity study of intravenous injections of OCaP1 for subjects with refractory osteosarcoma metastatic to lung. Hum Gene Ther 12: 1591-1593, 2001.

110.Li X, Jung C, Liu YH, Bae KH, Zhang YP, Zhang HJ, Vanderputten D, Jeng MH, Gardner TA and Kao C: Anti-tumor efficacy of a transcriptional replication-competent adenovirus, Ad-OC-E1a, for osteosarcoma pulmonary metastasis. J Gene Med 8: 679-689, 2006.
111. Kim NW, Piatyszek MA, Prowse KR, Harley CB, West MD, Ho PL, Coviello GM, Wright WE, Weinrich SL and Shay JW: Specific association of human telomerase activity with immortal cells and cancer. Science 266: 2011-2015, 1994.

112. Shay JW and Bacchetti S: A survey of telomerase activity in human cancer. Eur J Cancer 33: 787-791, 1997.

113. Li G, Kawashima H, Ogose A, Ariizumi T, Xu Y, Hotta T, Urata Y, Fujiwara T and Endo N: Efficient virotherapy for osteosarcoma by telomerase-specific oncolytic adenovirus. J Cancer Res Clin Oncol 137: 1037-1051, 2011.

114. Xie YF, Sheng W, Xiang J, Zhang H, Ye Z and Yang J: Adenovirus-mediated ING4 expression suppresses pancreatic carcinoma cell growth via induction of cell-cycle alteration, apoptosis, and inhibition of tumor angiogenesis. Cancer Biother Radiopharm 24: 261-269, 2009.

115. Xu M, Xie Y, Sheng W, Miao J and Yang J: Adenovirus-mediated ING4 gene transfer in osteosarcoma suppresses tumor growth via induction of apoptosis and inhibition of tumor angiogenesis. Technol Cancer Res Treat 14: 369-378, 2014.

116. Miranda CA, Lima EG, de Lima DB, Cobucci RN, Cornetta Mda C, Fernandes TA, de Azevedo PR, de Azevedo JC, de Araújo JM and Fernandes JV: Genital infection with herpes simplex virus types 1 and 2 in women from natal, Brazil. ISRN Obstet Gynecol 2014: 323657, 2014.

117. Liu S, Dai M, You L and Zhao Y: Advance in herpes simplex viruses for cancer therapy. Sci China Life Sci 56: 298-305, 2013

118. Hingorani P, Sampson V, Lettieri C and Kolb EA: Oncolytic viruses for potential osteosarcoma therapy. Adv Exp Med Biol 804: 259-283, 2014.

119. Smith KD, Mezhir JJ, Bickenbach K, Veerapong J, Charron J, Posner MC, Roizman B and Weichselbaum RR: Activated MEK suppresses activation of PKR and enables efficient replication and in vivo oncolysis by Deltagamma(1)34.5 mutants of herpes simplex virus 1. J Virol 80: 1110-1120, 2006.

120. Kelly KJ, Wong J and Fong Y: Herpes simplex virus NV1020 as a novel and promising therapy for hepatic malignancy. Expert Opin Investig Drugs 17: 1105-1113, 2008

121. Kroeger KM, Muhammad AK, Baker GJ, Assi H, Wibowo MK, Xiong W, Yagiz K, Candolfi M, Lowenstein PR and Castro MG: Gene therapy and virotherapy: Novel therapeutic approaches for brain tumors. Discov Med 10: 293-304, 2010.

122. Bharatan NS, Currier MA and Cripe TP: Differential susceptibility of pediatric sarcoma cells to oncolysis by conditionally replication-competent herpes simplex viruses. J Pediatr Hematol Oncol 24: 447-453, 2002

123. He S, Li P, Chen CH, Bakst RL, Chernichenko N, Yu YA, Chen N, Szalay AA, Yu Z, Fong Y and Wong RJ: Effective oncolytic vaccinia therapy for human sarcomas. J Surg Res 175: e53-e60, 2012

124. Pollack SM, Loggers ET, Rodler ET, Yee C and Jones RL: Immune-based therapies for sarcoma. Sarcoma 2011: 438940, 2011. 